\title{
O itinerário terapêutico: história oral de idosos com câncer*
}

\author{
Therapeutic itinerary: oral history of elderly patients with cancer
}

Itinerario terapéutico: historia oral de ancianos con cáncer

\author{
Angelita Visentin ${ }^{1}$, Maria Helena Lenardt ${ }^{2}$
}

\begin{abstract}
RESUMO
Objetivo: Conhecer e descrever o itinerário terapêutico de idosos com câncer em atendimento ambulatorial, hospedados em Casas de Apoio na cidade de Curitiba - Paraná. Métodos: Pesquisa qualitativa com abordagem fundamentada no método da História Oral Temática (HOT). Foram realizadas cinco entrevistas com idosos em tratamento oncológico. As análises das narrativas foram realizadas por meio da técnica específica da HOT. Resultados: Emergiram cinco tons vitais e um tema central. Conclusão: A análise das narrativas evidenciou a passagem dos idosos pelos subsistemas de cuidado à saúde. O itinerário terapêutico do idoso com câncer foi cercado de incerteza, dor, espera e tristeza. A esperança, família e Deus foram as garantias de superação da doença. A enfermagem deve reconhecer o itinerário terapêutico percorrido pelo idoso para planejar cuidados adequados dentro da realidade sócio-cultural, perpassando pelos subsistemas de cuidado à saúde.

Descritores: Idoso; Neoplasias; Enfermagem oncológica
\end{abstract}

\begin{abstract}
Objective: To identify and describe the therapeutic itinerary of elderly patients with cancer treated in outpatient services and hosted in support homes, in the city of Curitiba, state of Paraná. Methods: It was performed a qualitative research with an approach based on the method of Oral History Theme (HOT). Five interviews were held with elders who were in treatment for cancer. The analysis of the stories was made by means of the specific technique of HOT. Results: It was found five main tones and a central theme. Conclusion: The stories analysis showed the path the elders must follow in the subsystems of health care. Therapeutic itinerary of the elderly with cancer was surrounded by doubts, pain, hopes and sadness. Hope in the family and God were the guarantees to overcome the disease. The nurse must know the therapeutic itinerary followed by the elderly to plan the appropriate care, within the social-cultural reality in which subsystems act in health care.
\end{abstract}

Keywords: Aged; Neoplasms; Oncology nursing

\section{RESUMEN}

Objetivo: Conocer y describir los itinerarios terapéuticos de ancianos con cáncer, atendidos en ambulatorios y hospedados en casas de apoyo en la ciudad de Curitiba, en Paraná. Métodos: Se trata de una investigación cualitativa con abordaje basado en el método de la Historia Oral Temática (HOT). Fueron realizadas cinco entrevistas con ancianos que se encontraban en tratamiento oncológico. Los análisis de las narraciones fueron realizados por medio de la técnica específica de la HOT. Resultados: Surgieron cinco tonos vitales y un tema central. Conclusión: El análisis de las narraciones colocó en evidencia el recorrido de los ancianos por los subsistemas de cuidado de la salud. El itinerario terapéutico del anciano con cáncer estuvo cercado de dudas, dolor, espera y tristeza. La esperanza en la familia y en Dios fueron las garantías para superar la enfermedad. La enfermería debe conocer el itinerario terapéutico recorrido por el anciano para poder planificar los cuidados adecuados dentro de la realidad sociocultural en la que se encuentran los subsistemas de cuidado a la salud.

Descriptores: Edad; Neoplasias; Enfermería oncológica

* Trabalho desenvolvido em duas Casas de Apoio, mistas, que recebem doentes do interior do Estado do Paraná e de outros Estados.

${ }^{1}$ Mestre em Enfermagem pela Universidade Federal do Paraná - UFPR - Curitiba (PR), Brasil.

${ }^{2}$ Doutora em Enfermagem. Professora do Programa de Pós-Graduação de Mestrado em Enfermagem da Universidade Federal do Paraná - UFPR - Curitiba (PR), Brasil. 


\section{INTRODUÇÃO}

No Brasil, observa-se aumento significativo de estudos que abordam o envelhecimento e suas repercussões na saúde e, por meio destes, releva-se o movimento crescente de conscientização acerca das necessidades específicas de cada idoso.

Apesar de constituir processo natural, o envelhecimento não ocorre de forma homogênea. Cada idoso é um ser único que ao longo de sua vida foi influenciado por eventos de natureza fisiológica, psicológica, sociológica, cultural e econômica, que podem atuar sobre a qualidade de vida na velhice ${ }^{(1)}$. O processo de envelhecimento repercute em inúmeras modificações que ocorrem na saúde, em especial as denominadas doenças crônicas nãotransmissíveis, entre elas o câncer.

A oncologia e o envelhecimento relacionam-se de forma direta. O número de casos de câncer aumenta proporcionalmente à idade, sendo assim, quanto mais a população se torna envelhecida, a tendência no crescimento do número de casos de câncer se confirma. O câncer produz enorme impacto na geriatria e gerontologia de todo o mundo. Vivenciar essa realidade implica repensar os cuidados e implementar novas estratégias que visem o melhor atendimento a essa parcela da população. São inovações que solicitam um olhar atento para a história de vida de cada idoso e, conseqüentemente, os diversos modos pessoais dele se cuidar e buscar tratamento para sua doença.

$\mathrm{Na}$ dimensão biológica do cuidado, a enfermagem reconhece a importância das diversas formas para se tratar o câncer, como a cirurgia, a quimioterapia e a radioterapia. No entanto, as prioridades não recaem somente na eficácia destes tratamentos. É preciso se estender aos modos de cuidar e tratar a enfermidade pelo idoso. Avaliar os contextos e as experiências perpassadas pelo idoso na busca da terapêutica é condição imprescindível para se planejar o cuidado e tratamento adequado.

A pessoa que adoece perpassa um itinerário de cuidado da saúde em busca de orientações, explicações e tratamento para sua doença. A estrutura interna do sistema de saúde é descrita ${ }^{(2)}$ como um sistema cultural local, formado por três subsistemas inter-relacionados e interagindo através da passagem das pessoas por eles: subsistema profissional (profissões de cura organizadas, legalmente reconhecidas, com aprendizagem formal e registros sistemáticos extremamente desenvolvidos), subsistema popular (arena da cultura popular, do conhecimento leigo, não profissional, não especialista, no qual as doenças são primariamente identificadas e enfrentadas) e subsistema folclórico (especialistas em cura, não profissionais, não reconhecidos legalmente e com registros limitados de seu conhecimento).

Através dos pressupostos constitutivos dos subsistemas, diferentes indivíduos e grupos sociais constroem suas concepções de tratamento e cura, ingressam e fazem escolhas neles. A investigação sobre o itinerário terapêutico dos idosos possibilita aos profissionais da área conhecer como a pessoa doente percebe, vive e reage diante dos sinais, sintomas e da incapacidade provocada pela doença, em especial a doença oncológica.

Diante do exposto, o objetivo deste trabalho foi: Conhecer e descrever o itinerário terapêutico de idosos com câncer em atendimento ambulatorial, hospedados em Casas de Apoio, na cidade de Curitiba - Paraná.

\section{MÉTODOS}

Trata-se de pesquisa qualitativa, centrada no método da história oral temática, em que se considera o sujeito do estudo o idoso com câncer. A abordagem qualitativa enfatiza o mundo das ações e das relações humanas, um aspecto não perceptível ou captável quantitativamente. Dessa forma, a utilização da pesquisa qualitativa pode responder a questões específicas, em um contexto de realidade que não pode ser quantificada ${ }^{(3)}$.

O método da história oral temática permite compreender o passado por meio de coleta, organização e interpretação dos fatos; parte de um assunto específico e preestabelecido e se compromete com o esclarecimento ou opinião do entrevistado sobre algum evento definido ${ }^{(4)}$.

O estudo foi desenvolvido em duas Casas de Apoio, mistas, que recebem doentes do interior do Estado do Paraná e de outros Estados. A colônia escolhida foi de cinco idosos, que apresentavam diagnóstico de câncer, que se hospedavam nestas Casas e estavam submetidos a tratamento na instituição de referência para o atendimento oncológico.

Os critérios de inclusão determinaram a rede de entrevistados: total de cinco idosos, de ambos os sexos, com idade igual ou superior a 65 anos; tempo de diagnóstico não superior a três anos; sem alteração do nível cognitivo e não ser portador de demência, segundo resultados da aplicação do teste minimental ${ }^{(5)}$; não constar no prontuário médico o registro: "paciente fora de possibilidade terapêutica"; ouvir e falar sem dificuldades; permitir a gravação da entrevista; estar em tratamento para o câncer na instituição de referência para o desenvolvimento do estudo; permanecer hospedado para tratamento ambulatorial nas Casas de Apoio selecionadas para o estudo; apresentar registro em prontuário da instituição da comunicação do diagnóstico de câncer ou da ciência do mesmo pelo idoso; estar acompanhado de um familiar durante o período de hospedagem para tratamento do câncer.

A coleta das informações ocorreu por meio de gravação da entrevista semi-estruturada e das anotações de campo. Foi realizada no período de agosto a outubro de 2007, em dias alternados. A entrevista foi realizada, 
partindo de duas questões norteadoras: Conte-me como $\mathrm{o}$ (a) senhor(a) descobriu que estava doente? O que o(a) senhor(a) fez para tratar e cuidar da doença? As anotações de campo focalizaram, além de detalhes dos locais da entrevista, a postura adotada durante a coleta das narrativas, como gestos, sinais corporais, mudança no tom de voz, ou seja, elementos significativos para a interpretação posterior dos depoimentos. Ressalta-se que, durante as entrevistas, o processo de interação entre entrevistado e entrevistador foi primordial.

Os processos analíticos e o modo de apresentação das narrativas foram realizados através do método de categorização ${ }^{(3)}$. Para análise das narrativas foram seguidas as fases de transcrição, textualização e transcriação ${ }^{(4)}$ das entrevistas. O texto final foi levado para a conferência do idoso, antes da sua utilização no desenvolvimento da pesquisa.

O projeto de pesquisa foi aprovado pelo Comitê de Ética em Pesquisas (CEP) da Liga Paranaense de Combate ao Câncer e registrado sob o n. ${ }^{\circ} 1534$. A pesquisa teve início somente após o parecer positivo do CEP, conforme recomendações da Resolução n. ${ }^{\circ}$ 196/1996 do Conselho Nacional de Saúde ${ }^{(6)}$. Durante, a interpretação das informações, a identificação dos idosos foi por meio de um número seqüencial, conforme a ordem em que ocorreram as entrevistas.

\section{RESULTADOS}

Construiu-se o itinerário terapêutico do paciente idoso com câncer em cinco categorias e seus tons vitais provenientes das falas dos idosos e um tema central. Conforme segue:

Categoria 1: A manifestação da doença/ enfermidade.

TOM VITAL 1: "Eu antigamente achava que o câncer só dava em ferida."

"Nunca ninguém me explicou que poderia comescar assim, de um tumorzinho, uma bolinha diferente. Eu antigamente achava que o câncer só dava em ferida."(Idosa 1, 65 anos, 08/08/07 e 31/08/07)

"A gente volta e meia se sente mal. Parece que alguma coisa não vai bem. A gente nunca pensa no pior."(Idoso 2, 70 anos, 09/ 08/07 e 30/08/07)

"Para nós que sempre trabalhamos muito, sentir que alguma coisa não vai bem é normal." (Idosa 3, 69 anos, 17/08/07)

"Eu conhecia, mas não sabia como se pegava direito e ainda não sei como foi acontecer comigo, como eu peguei." (Idosa 4, 73 anos, 29/09/07)

"Essa doença matadeira é difícil de saber quando você tem, no início, e depois chega como eu no hospital e nos médicos." (Idoso 5, 77 anos, 01/10/07)

As explicações da doença, de sua origem e tratamentos estão ligadas diretamente às crenças e valores dos idosos, que geram o sistema de conhecimento, a respeito da estrutura e do funcionamento do corpo, e isto foi manifestado nas cinco entrevistas.

Sentir-se mal não tem importância, é coisa corriqueira, não permanece no corpo por muito tempo, passa rápido e não é doença que se deve prestar atenção. Não estar bem é uma realidade cotidiana, pois a maioria apresenta doenças como a hipertensão e o diabete mellitus e ainda comorbidades decorrentes das mesmas.

Para os idosos, as doenças que não são visíveis, não apresentam grau importante de comprometimento. Os sinais de doença grave precisam se manifestar, demarcar. A idosa, quando nomeia o câncer como uma ferida, comunica uma mensagem que dá significado à doença. O seu sistema de conhecimento interpreta o câncer como algo visível, que se pode ver. Entretanto, seu câncer não se manifestou como ferida. Este sinal não apareceu, não atribuiu sentido ao significado do câncer e, hoje, o câncer é um mistério.

O não entendimento da gravidade dos sinais e sintomas do câncer dificultou e retardou o atendimento. Relacionar o "sentir-se mal" às doenças menos graves é comum entre os idosos, pois nunca se pensa no pior.

O desconhecimento, na sua totalidade, da origem do câncer, a respeito de seus tratamentos e cuidados desencadeia muitas interpretações. A narrativa da idosa 4 revela o câncer como doença contagiosa e não entende como "pegou ela" e por isso a doença é um mistério em sua vida; incapaz de explicar e compreender como foi essa transmissão.

$O$ câncer tem um sinal informante de doença matadeira, como expressado pelo idoso 5. O estar com câncer ainda relaciona-se diretamente ao trágico como a morte e o sofrimento, que são elementos pouco conhecidos e que geram medo. No senso comum, a palavra câncer está intimamente associada a idéia de dor e morte. Sempre se atribui que o câncer é extremamente doloroso e que dele advém uma morte horrível ${ }^{(7)}$.

Para o profissional da saúde, é fundamental conhecer e interpretar as atitudes das pessoas frente à experiência da doença, pois significam informações que oferecem parte da direção a ser tomada nas orientações de cuidado. $\mathrm{Na}$ perspectiva do idoso, está diretamente relacionada com a sua experiência e interpretações particulares sobre a origem e o significado dos sinais e sintomas no contexto da doença.

Categoria 2: O subsistema profissional no itinerário do tratamento do câncer.

TOM VITAL 2: "A gente sóprocura o médico quando precisa mesmo."

"Esse é um dos problemas de hoje, ficam mandando a gente de um lado para outro. Os tratamentos que en faço são dolorosos, $e$ você nunca sabe o que esperar deles ou aonde eles vão levar. Apesar 
de triste, confio em Deus e nos médicos”.'(Idosa 1, 65 anos, 08/ 08/07 e 31/08/07)

"A gente só procura o médico quando precisa mesmo. Ficam passando a gente de um lugar para outro, como uma bola. Quando eu fui ao médico, ele não perguntou muito, porque tem que ser rápido. Então, a gente não fala tudo o que aconteceu.'”( Idoso 2, 70 anos, 09/08/07 e 30/08/07)

"Os caminhos para se chegar ao tratamento certo não são curtos, não; demora muito, e são poucos os que conseguem e não se perdem por aí”. ( Idosa 3, 69 anos, 17/08/07)

"Procurar o médico é custoso para nós." ( Idosa 4, 73 anos, 29/09/07)

"Eu fui mesmo porque estava precisando, se pudesse escolher, eu não iria, não. Eu não gosto de médicos." (Idoso 5, 77 anos, 01/10/07)

No itinerário terapêutico dos idosos evidencia-se o subsistema profissional, com aquelas características próprias, em que prevalece a visão fragmentada das várias especialidades, que origina encaminhamentos e triagens inadequadas. Ainda, um sistema de atendimento em que os idosos encontram muitas dificuldades para conseguirem ajuda médica qualificada.

O processo de diagnóstico é o período mais difícil e angustiante para os idosos. No entanto, após serem encaminhados à instituição hospitalar para o tratamento do câncer, fatores como a ansiedade, a dor e o desconhecimento da doença são problemas que estão longe de serem sanados. O tempo entre o primeiro atendimento médico, idas e vindas aos profissionais e a chegada ao hospital de referência para o atendimento oncológico perdura meses e gera sentimentos de incerteza, insegurança e ansiedade ao idoso, família e membros de seu pertencimento.

Alguns estudos demonstraram que algumas pessoas consultam o médico assim que aparecem os primeiros sinais e sintomas de doença, já outras, com sintomas semelhantes, não o fazem, em razão das dificuldades financeiras para chegar ao atendimento profissional ${ }^{(8)}$. Constata-se que as dificuldades financeiras foram apontadas, e enfatizadas quando o atendimento pelo subsistema profissional não é procedido com acerto, e acarreta evolução rápida da doença para fases de tratamentos que exijam mais cuidados e dispêndio financeiro.

A biomedicina é reconhecida como representante do conhecimento da área da saúde. O subsistema profissional é o subsistema de cuidado à saúde mais difundido e, dominante de tratamento, e que em geral é procurado nas disfunções graves de saúde e tem apresentado alto índice de cura, especialmente na área oncológica. Apesar dos grandes avanços neste modelo, as pessoas persistem com suas crenças e explicações para suas doenças, também em outros sistemas de conhecimentos.

Categoria 3: Convivendo com a doença

TOM VITAL 3: "Desde que eu descobri que estava doente, minha vida e a da minha familia nunca mais foi a mesma."

"O dinheiro da aposentadoria mal dá para comprar os remédios. E épara a vida toda, é o caminho que é da gente. '( Idosa 1, 65 anos, 08/08/07 e 31/08/07)

"Tenho que me cuidar com o que eu como para não passar mal. Então, não é tudo normal como era antes. '( Idoso 2, 70 anos, 09/08/07 e 30/08/07)

"Alguns remédios a gente consegue pegar de graça no hospital porque com o salário de aposentada não dá. O pior é saber que isso ainda vai durar por muito tempo.'( Idosa 3, 69 anos, 17/08/07)

'Não sei até quando vou agüentar. A gente não agüenta pela gente mesmo e sim pela família da gente que não deixa desistir. Como eu já te falei antes, eu tô cansada de tomar remédios, vir ao hospital e ficar dependendo de todo mundo até para ir ao banbeiro, e mesmo assim criou raiz. Fico muito triste de saber que isso tudo não tem data para terminar. Tenho vontade de terminar. Tomara que eu consiga e volte para te contar depois, em outra história”.'(Idosa 4, 73 anos, 29/09/07)

"Depois que apareceu esta doença fiquei mais magro, não consigo comer direito. Tem que ficar tomando remédio a toda hora. "( Idoso 5, 77 anos, 01/10/07)

Os idosos têm conhecimento e consciência de que, após o descobrimento do câncer, há a introdução de novas incumbências, perdas e constantes ameaças em suas vidas. As perdas são suportadas, porque a família se envolve, muda as rotinas de cada membro, e dá sustentação e proteção de vida ao seu doente.

O descobrimento de uma condição crônica de saúde, em especial uma doença oncológica, altera significativamente a vida, tanto do idoso quanto da família e suas relações. Para o idoso, mesmo que o suporte familiar lhe traga a proteção desejada, o fato do seu problema de saúde não ser passageiro o incomoda, porque altera o processo de viver das pessoas que lhe dão carinho e atenção.

As narrativas dos idosos entrevistados corroboram as citações de novas incumbências, perdas e ameaças evidenciadas no estilo de vida de pessoas em condições crônicas de saúde ${ }^{(9)}$. Essas alterações puderam ser identificadas nas falas dos idosos como: Novas incumbências: a partir do diagnóstico de condição crônica, introduziram-se novas atividades no dia a dia, tais como: tomar medicação, fazer dieta, fazer controles médicos e laboratoriais periodicamente, fazer exercícios físicos e controle dos sintomas. Perdas: de ordem financeira, determinadas pelo afastamento do trabalho, aposentadoria precoce e gastos com medicações de alto custo, além do necessário para despesas com transporte e alimentação durante o período do tratamento. O sentimento de perda refere-se também às relações sociais, com os próprios familiares, caracterizadas por mudanças de papéis na família e a comunidade, devido às limitações que os impedem de participar de atividades sociais. Ameaças: os idosos relataram estar constantemente 
ameaçados pelos sintomas da doença, pela limitação física e pela própria morte.

Categoria 4: Subsistema folclórico: presença constante no itinerário de tratamento do câncer.

TOM VITAL 4: "Mas ele disse que muita gente está se acudindo com esse remédio."

"Estou tomando agora remédio natural. Eu tomo os da medicina e tomo esse também. Sempre um junto com o outro. Tem um dentista lá que ele extrai, tira um leite de uma planta, de uma madeira natural." (Idosa 1, 65 anos, 08/08/07 e 31/08/07)

"Muita gente disse para eu ir benzer que o mal ia embora. Fiquei indo durante sete dias e tomei um remédio que ele mesmo fazia, é assim, tipo uma garrafada que chama, não sei se você conhece. Mas ele disse que muita gente está se acudindo com esse remédio. Tenho esperança em um dia terminar tudo isso. O meu Deus já me teston o suficiente. Agora eu tenho que colocar na cabeça que Deus já me curou e colocar Deus nas mãos dos médicos". (Idoso 2, 70 anos, 09/08/07)

"Então minha vizinha conhecia uma mulher que ajuda a tirar essas coisas ruins, ajuda a gente a melhorar. Eu fui lá. Ela me benzeu."( Idosa 3, 69 anos, 17/08/07)

"Todos, desde a mãe da gente, os vizinhos e os conbecidos sabiam de alguma erva ou de uma reza que ajudava na doenç. Tinha problema de intestino, tinha uma erva. Tinha problema de cabeça, fazia uma compressa na cabeça."( Idosa 4, 73 anos, 29/09/07)

"Na minha cidade, o meu vizinho conbece e se curou nesses homens que fazem essas cirurgias pelos espiritos. Eu lembro que ele passon mal. Ele me benzeu. Passou uma água de um vidro, que tinha umas ervas, pelo corpo todo. Parecia que rezava em uma lingua que eu não entendia nada."( Idoso 5, 77 anos, 01/10/07)

A passagem da doença à saúde pode vir a corresponder a uma reorientação mais completa do comportamento do doente, na medida em que transforma a perspectiva na qual este percebe seu mundo e se relaciona com os outros a sua volta ${ }^{(10)}$. A busca da cura muitas vezes faz com que a pessoa doente ou a família percorra várias alternativas dentro de sua religiosidade e fora dela. Outras possibilidades foram descritas durante as entrevistas, como as dos curandeiros, significando a fusão de crenças num verdadeiro sincretismo religioso.

Em todos os agrupamentos humanos destacam-se pessoas que desenvolvem atividades de parteiras, rezadeiras, garrafeiras, raizeiros, entre outros, que são, em geral, procurados para aconselhamentos, diagnósticos e tratamentos das doenças. Essas pessoas se utilizam do conhecimento popular para sugerir a utilização de métodos terapêuticos, os mais diversificados, tais como uso de chás, cozimentos, garrafadas, entre outros ${ }^{(10)}$. Uma das práticas mais difundidas da medicina religiosa ocorre através de grupos de reza, benzedeiras e benzedores que se utilizam de tradições como os rituais. Estas práticas foram procuradas pelos cinco participantes do estudo, embora alegassem certa descrença na benzedeira. A justificativa pela procura da benzedeira foi a tradição familiar.

O paciente encontra em um curandeiro, ao contrário do que encontra em um médico, alguém que teria uma experiência de vida semelhante, que falaria a mesma linguagem e poderia compreendê-lo. A doença não seria algo observado somente biológica e sintomaticamente, mas envolveria aspectos sociais, culturais e psicológicos ${ }^{(11)}$.

A crença em rezadeiras possui uma dimensão significativa no processo de cura das doenças. É através desses sábios populares que a medicina popular deixa de ser um conjunto fragmentado de práticas de cura, para se tornar um sistema complexo e articulado de conhecimentos sobre a vida, a doença e a morte ${ }^{(12)}$.

Categoria 5: Subsistema popular: seio, esteio e direção TOM VITAL 5: "Mas a família é a base de tudo. É onde você pisa para se apoiar e onde apóia os que vêm depois."

"O meu velho me ajuda quando eu preciso. Eu estou aqui e en trago ele sempre comigo, não deixo ele em casa sozinho, não. Os meus filhos gostam muito de mim. Eu não sei o que seria de mim sem eles"( Idosa 1, 65 anos, 08/08/07 e 31/08/07)

"O meu neto vem comigo, mas eu fico um pouco triste porque ele perde aula. A minha filha mais velha não pode vir por causa do trabalho, então ele vem. O meu filho, ele tem medo de tudo."( Idoso 2, 70 anos, 09/08/07)

"Elas não me deixam vir sozinha, não, não. Essa é solteira, mas a outra quando vem deixa o marido em casa com os filhos. A gente não pede nada disso, mas é muito bom ter alguém da família com a gente. Ai, não se sente sozinha. Sabe que tem companbia. Mas a família é a base de tudo. É onde você pisa para se apoiar e onde apóia os que vêm depois. A família é meu suporte. Eu tenho medo de deixá-los, mas tenho fé de que isso vai demorar muito ainda. Porque Deus deixon a gente mais unido ainda e ele sempre nos protegeu e vai continuar nos protegendo. Tenho fé e esperança de ficar curada para sempre". (Idosa 3, 69 anos, 17/08/07)

"Na minha família, todos sempre foram unidos. Não tem essa história de irmão brigando com irmão e um não fala com a mulher do outro e assim vai, como a gente vê em algumas familias. Eu acredito que sempre em uma ocasião de doença as pessoas ficam mais juntas." (Idosa 4, 73 anos, 29/09/07)

"Eu sou muito unido com meus filhos. Tenho dois filhos bomens e três filhas mulheres, mas os homens se entendem melhor. As mulheres cuidam mais da gente, mas com os filhos eu consigo conversar melhor estas coisas de homem. Mulher não entende disso. Quando eu fiquei com essa doença, fiz coisas para me curar que nem imaginaria (risos) até me benzer com aquela mulher en fui (risos). É muito bom saber que a familia da gente apóia em tudo, meu filho até foi junto (à benzedeira). Tenho fé em Deus que vai dar certo e eu não precisarei mais passar por tudo isso e vou sobreviver para poder contar e derrubar esta doença que derruba a gente ". (Idoso 5, 77 anos, 01/10/07)

Diante de um problema de saúde, a família avalia as alternativas, faz escolhas, toma decisões, mobiliza recursos 
pessoais e materiais de que dispõe. As decisões quanto ao itinerário terapêutico foram sempre realizadas junto aos filhos, em família. A preocupação com a saúde do idoso na família é exacerbada em presença de doença oncológica, pois representa doença grave, que compromete a vida. As narrativas apontaram, de modo absoluto, que a família é a sustentação e direção para minimizar os sofrimentos. Os membros familiares também foram fundamentais para estimularem as atitudes de enfrentamento no idoso com câncer.

No momento atual, quando as pessoas tendem a valorizar o individual, "o núcleo familiar continua sendo de incontestável importância no equilíbrio do homem, mantendo-o ligado a laços fortes que se fazem evidentes nos momentos de dificuldades"(12).

TEMA: A esperança, para o idoso, sustenta a garantia do tratamento do câncer no entrelaçar dos subsistemas.

Sobreviver a este percalço da vida para o idoso que está com câncer significa intensificar o sentimento de esperança. É poder continuar a usufruir e a desfrutar da convivência harmônica com Deus, com a família e consigo mesmo. $\mathrm{O}$ ato de esperar o que se deseja traz ao idoso a necessidade de garantias para sustentar esta espera. As garantias o conduzem a ter esperança de conseguir o que ele mais deseja: superar o câncer. As garantias estão firmemente ancoradas no sagrado, na família, nos profissionais e em pessoas próximas a ele. A esperança é compartilhada por meio das orações dos vizinhos, amigos e comunidade a qual pertence.

A esperança é a segunda das três virtudes teologais e é simbolizada por uma âncora. Considera-se a esperança como a âncora das almas. As provações não são facilmente entendidas, a não ser com base na fé e esperança, porque freqüentemente há um propósito maior que não se pode compreender. A esperança proporciona paz.

Nas narrativas dos idosos está implícita a asserção: onde há esperança não se vive em desespero. Sem esperança, não se consegue perseverar até o fim. Aprende a rezar quando fica doente. Reforça sua religiosidade e esta mudança também pode ter início e/ou refletir na família, quando seus membros direcionam a necessidade de curandeiros e de voltar-se à igreja ao mesmo tempo.

"Na cultura brasileira, o sofrimento quase sempre é explicado como uma imposição de Deus ao homem. "Vivemos num vale de lágimas" e, portanto, o nosso destino é o sofrimento. Esse modo de pensar, de interpretar os fatos, tem levado alguns doentes a uma condição de desespero, de revolta contra o Criador. [...] O homem foi criado para ser feliz, caso contrário teríamos que admitir um Criador imperfeito, sádico ou, no mínimo, mal-humorado"(13).

A esperança jamais foi perdida nas famílias dos idosos e, em nenhum momento suas narrativas demonstraram descaso ou desanimo de um familiar em apoiar o idoso no tratamento, apesar das adversidades como a distância, as dificuldades econômicas, de transporte, de acomodação, entre outras. Nada disso abala a esperança de terminar o tratamento e voltar para sua vida cotidiana, cuidando de seus animais e plantas ou fazendo atividades como de costume. A esperança é a mola propulsora que garante o itinerário de tratamento do idoso com câncer.

\section{DISCUSSÃO}

Desde o início da pesquisa, pode-se perceber o quanto é vasto e atraente o universo dos idosos que têm tanto a ensinar e a contar e, muitas vezes, não é dado o devido valor às suas experiências e conhecimentos. Oferecer a audição e se posicionar disposto a conversar, são simples atos. Os caminhos percorridos apresentaram-se cercados de emoção, momentos alegres, tristes e difíceis para agüentar tamanha emoção.

Nas páginas precedentes, ao conhecer o itinerário terapêutico utilizado pelos idosos com câncer evidenciamse as principais barreiras encontradas no cuidado, dificuldades advindas com a descoberta da doença e da procura de atendimento nos susbsistemas de cuidado à saúde, uma vez que essas dificuldades exarcebam-se com as limitações impostas pela idade e pela doença, levandoos muitas vezes ao sofrimento individual e familiar.

A constatação entre os paradigmas dos três subsistemas ${ }^{(2)}$ na prática clínica e na prestação de cuidados, bem como a percepção que o modelo biomédico não é o suficiente para abordar toda a problemática do paciente idoso com câncer, tem levado os profissionais da saúde a interessarem-se pelas dimensões sociais, culturais e até mesmo espirituais implicadas nos processos de cura.

Os profissionais muitas vezes advertem que os subsistemas familiar e folclórico ajudam a aumentar as complicações advindas da doença oncológica no idoso. Entretanto, neste estudo pode-se inferir que o subsistema profissional muitas vezes também contribuiu na evolução da doença. Confirma-se pelo atraso ou prolongamento do diagnóstico inicial ou pouco domínio sobre o tratamento e o curso da doença pelos profissionais.

Para o subsistema profissional, em especial para a enfermagem, conhecer o itinerário de cura percorrido pelo paciente idoso possibilita o planejamento dos cuidados dentro de uma realidade sócio-cultural dos pacientes e de suas famílias. Isto implica em valorizar o seu conhecimento cultural, conhecer os recursos utilizados nos itinerários de cura, acompanhar sua evolução, direcionar o atendimento para a desmistificação do câncer e de seus tratamentos e, ainda, identificar os recursos comunitários para apóia-los bem como o acesso a esses recursos como o auxílio das Casas de Apoio e programas como o Paraná Sem Dor. 
Os estudos apontam as grandes dificuldades enfrentadas pelas famílias destes idosos que precisam se deslocar de suas cidades ou áreas rurais para buscar atendimento de saúde nas grandes cidades. Entender estes obstáculos e suas relações sociais é parte do cuidado profissional que se faz necessário ao planejar uma assistência de enfermagem de excelência.

A complexidade e a particularidade que envolve a vida cotidiana e os processos de enfrentamento e de escolhas frente às doenças, em geral, não fazem parte da formação dos profissionais da saúde. Há uma diferença entre o raciocínio dos profissionais e os diversos grupos populares, o que aumenta a lacuna entre o profissional e o paciente.

\section{CONSIDERAÇÕES FINAIS}

A metodologia da história oral possibilitou um olhar mais atento às falas dos idosos. O conhecimento emergente dos idosos favorecem as trocas, com pesquisador, numa relação de efetiva aprendizagem. A escolha metodológica foi capaz de fornecer estímulos aos idosos para que se lembrassem do passado, do próprio caminho percorrido até o momento.

\section{REFERÊNCIAS}

1. Diogo MJDE. O papel da enfermeira na reabilitação do idoso. Rev Latinoam Enferm. 2000;8(1):75-81.

2. Kleinman A. Patients and healers in the context of culture: an exploration of the borderland between anthropology, medicine. and psychiatry. Berkeley: University of California Press; 1980.

3. Minayo MCS. O desafio do conhecimento: pesquisa qualitativa em saúde. 8a. ed. São Paulo: Hucitec; 2004.

4. Meihy JCSB. Manual de história oral. 5a. ed. São Paulo: Loyola; 2005.

5. Bertolucci PHF, Brucki SMD, Campacci SR, Juliano Y. O miniexame do estado mental em uma população geral: impacto da escolaridade. Arq Neuropsiquiatr. 1994;52(1):1-7.

6. Brasil. Ministério da Saúde. Conselho Nacional da Saúde. Comitê Nacional de Ética em Pesquisa em Seres Humanos. Resolução n 196 de 10 de outubro de 1996: diretrizes e normas regulamentadoras da pesquisa envolvendo seres humanos [Internet]. [citado 2007 Jan 24]. Disponível em: http://www.ufrgs.br/bioetica/res19696.htm

7. Ferreira J. O corpo sígnico. In: Alves PC, Minayo MCS, organizadores. Saúde e doença: um olhar antropológico.
Os depoimentos reforçam que os idosos com câncer, diante do diagnóstico médico, mantêm a determinação no seu conhecimento e nas suas crenças, e evidenciam o uso paralelo de práticas adquiridas culturalmente, aliando assim a terapêutica médica à popular, de forma complementar e não excludente.

O estudo aponta as grandes dificuldades enfrentadas pelas famílias destes idosos, que precisam se deslocar de suas cidades ou áreas rurais para buscar atendimento de saúde nas grandes cidades. Entender estes obstáculos e suas relações sociais é parte do cuidado profissional que se faz necessário ao planejar uma assistência de enfermagem de excelência.

Ressalta-se que a enfermeira, no desenvolvimento de sua prática profissional, muitas vezes tem utilizado, unicamente, concepções legitimadas pela ciência, estabelecendo relação de superioridade com o idoso, de modo diretivo e não sob demanda e, assim, promovendo certo distanciamento do idoso, inviabilizando o diálogo inter-cultural.

Frente ao complexo campo do itinerário terapêutico, ainda há várias interrogações e incertezas que devem permear novos estudos sobre o tema, principalmente na área de gerontologia, em especial na enfermagem.

Rio de Janeiro: Fiocruz; 1998.

8. Helman CG. Cultura, saúde e doença. Porto Alegre: Artes Médicas; 1994.

9. Silva DMGV. Desafios e enfrentamentos: um modelo de prática da enfermagem para indivíduos em condições crônicas de saúde [dissertação]. Florianópolis: Curso de PósGraduação de Enfermagem. Universidade Federal de Santa Catarina; 1990. $173 \mathrm{f}$.

10. Rabelo MCM. Religião, ritual e cura. In: Alves PC, Minayo MCS, organizadores. Saúde e doença: um olhar antropológico. Rio de Janeiro: Fiocruz; 1998.

11. Loyola MA. Médicos e curandeiros: conflito social e saúde. São Paulo: Difel; 1984.

12. Alves AR, et al. Saúde e doença: uma abordagem sociocultural. In: Silva YF, Franco MC, organizadoras. Saúde e doença: uma abordagem cultural da enfermagem. Florianópolis: Papa-Livros; 1996.

13. Lenardt MH. A hospitalização desnudando o microcosmo de uma unidade hospitalar [tese]. Florianópolis: Curso de Pós-Graduação em Enfermagem. Universidade Federal de Santa Catarina; $2001.158 \mathrm{f}$. 